\title{
Measurement of the metabolism of energy substrates in individual bovine blastocysts
}

\author{
D. Rieger* and P. Guay \\ Centre de recherche en reproduction animale, Faculté de médecine vétérinaire, \\ Université de Montréal, C.P. 5000, St-Hyacinthe, Québec, Canada J2S 7C6
}

\begin{abstract}
Summary. Individual blastocysts from cows were cultured for $3 \mathrm{~h}$ under $5 \% \mathrm{CO}_{2}$ in air, in $4 \mu \mathrm{l}$ droplets of Ham's F-10 medium containing $\mathrm{D}-\left[5-{ }^{3} \mathrm{H}\right]$ glucose, $\mathrm{D}-\left[1-{ }^{14} \mathrm{C}\right]$-glucose, $\mathrm{D}-\left[6-{ }^{14} \mathrm{C}\right]$ glucose, $\left[2-{ }^{14} \mathrm{C}\right]$ pyruvate, or $\mathrm{L}-\left[\mathrm{U}-{ }^{14} \mathrm{C}\right] \mathrm{glutamine}$, and with or without 2,4dinitrophenol (DNP) or phenazine ethosulphate (PES). The ${ }^{14} \mathrm{CO}_{2}$ or ${ }^{3} \mathrm{H}_{2} \mathrm{O}$ produced were collected by exchange with an outer bath of $400 \mu \mathrm{l} 25 \mathrm{mM}-\mathrm{NaHCO}_{3}$. All combinations of substrate and treatment (control, DNP or PES) produced measurable quantities of labelled product except for $D-\left[6-{ }^{14} \mathrm{C}\right]$ glucose in the presence of PES. Untreated and DNP-treated embryos developed normally during a subsequent 48 -h culture period in fresh medium, but PES-treated embryos degenerated. Pyruvate and glutamine metabolism both increased markedly in the presence of DNP, indicating that the Krebs' cycle is active, and that glutamine can be used as an energy substrate. Conversely, DNP has no significant effect on glucose metabolism, indicating that glycolysis is blocked in the bovine blastocyst due to a lack or inhibition of pyruvate kinase. The production of ${ }^{14} \mathrm{CO}_{2}$ from $\mathrm{D}-\left[1-{ }^{14} \mathrm{C}\right] \mathrm{glucose}$ increased significantly in the presence of PES, indicating that the activity of the pentose shunt is less than maximal.
\end{abstract}

Keywords: embryo; cattle; energy metabolism; glutamine

\section{Introduction}

The metabolic activity of mouse and rabbit embryos has been the subject of much study with respect to the uptake, and the metabolism or incorporation of a variety of glycolytic substrates and amino acids (see Biggers \& Stern, 1973; Wales, 1975; Pike, 1981; Rieger, 1984). However, little study has been made of the metabolic activity of the embryos of cows or other domestic animals. In view of the fact that the general energy metabolism of the cow, and both the timing of development of the bovine embryo and its interaction with the uterus differ significantly from those of laboratory species, a better understanding of the metabolism of the bovine embryo is needed.

Renard et al. (1978) evaluated the metabolic activity of individual cattle embryos by measuring the concentration of energy substrates in the medium before and after culture. They showed significant metabolism of glucose and lactate by Day-10 embryos but their system was not sufficiently sensitive to detect metabolic activity in individual Day-7 embryos (Renard et al., 1982). Conversely, we have previously shown that measurable amounts of ${ }^{14} \mathrm{CO}_{2}$ are produced from ${ }^{14} \mathrm{C}$-labelled glucose by individual cattle (Rieger, 1984) and horse (Rieger et al., 1987) Day-7 embryos.

The present report describes a series of experiments in which individual cattle blastocysts were cultured with radiolabelled substrates in a defined medium so that activities of the Embden Meyerhof pathway, the pentose shunt, and the Krebs' cycle could be measured. In addition to

\footnotetext{
*Present address: Department of Biomedical Sciences, Ontario Veterinary College, University of Guelph, Guelph,
} Ontario, Canada N1G 2W1. 


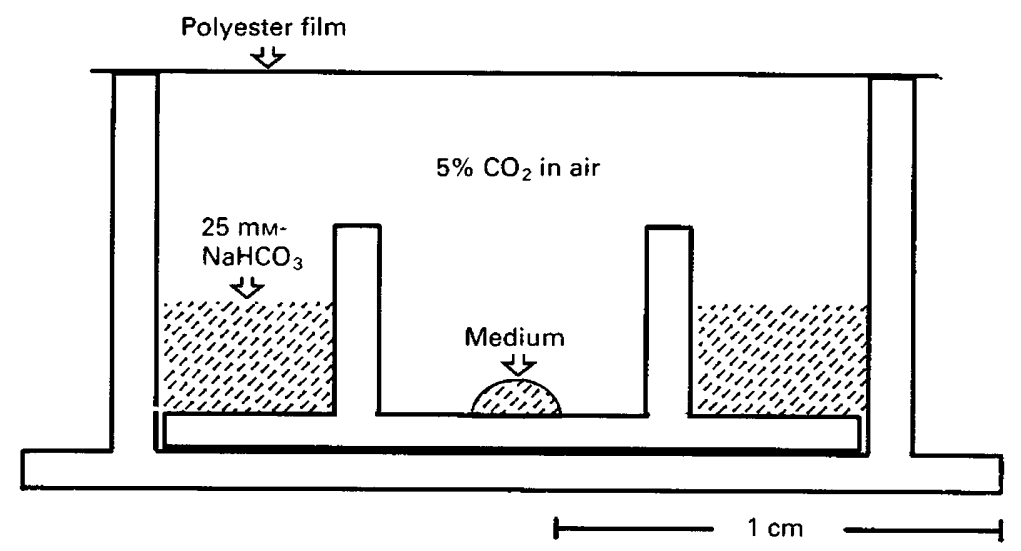

Fig. 1. Diagram of the culture apparatus used for the measurement of the metabolic activity of individual cattle blastocysts. The $4 \mu \mathrm{l}$ droplet of Ham's F-10 medium contained one embryo, together with a radiolabelled substrate, with or without DNP or PES. The ${ }^{14} \mathrm{CO}_{2}$ or ${ }^{3} \mathrm{H}_{2} \mathrm{O}$ produced during the 3-h incubation period exchanged with the bicarbonate or water in the external bath of $400 \mu$ sodium bicarbonate.

glucose and pyruvate, we also investigated the metabolism of glutamine, for two reasons. Firstly, the ultimate catabolism of glutamine is exclusively mitochondrial and therefore its metabolism reflects the activity of the Krebs' cycle. Secondly, Carney \& Bavister (1987) have shown that glutamine is an absolute requirement for development of the early hamster embryo, unrelated to protein synthesis. It is therefore of interest to know whether glutamine might serve as an energy substrate for mammalian embryos. Dinitrophenol, an uncoupler of oxidative phosphorylation, and phenazine ethosulphate, which oxidizes NADPH, were used to evaluate the metabolic potential of the Krebs' cycle and the pentose shunt, respectively.

\section{Materials and Methods}

Materials. Ham's F-10 medium was purchased from Flow Laboratories (McClean, VA, U.S.A.). Penicillin, streptomycin and $N$-2-hydroxyethylpiperazine- $N^{\prime}$-2-ethanesulphonic acid (Hepes) were obtained from Gibco Laboratories (Grand Island, NY, U.S.A.). Essentially fatty acid-free bovine serum albumin (BSA), 2,4-dinitrophenol (DNP) and phenazine ethosulphate (PES) came from Sigma Chemical Co. (St Louis, MO, U.S.A.). D- $\left[1{ }^{14} \mathrm{C}\right]$ Glucose (sp. act. $54.6 \mathrm{mCi} / \mathrm{mmol}), \mathrm{D}-\left[6-{ }^{14} \mathrm{C}\right] \mathrm{glucose}(\mathrm{sp}$. act. $57.0 \mathrm{mCi} / \mathrm{mmol}),\left[2-{ }^{14} \mathrm{C}\right]$ pyruvate $(\mathrm{sp}$. act. $7.5 \mathrm{mCi} / \mathrm{mmol}), \mathrm{L}-\left[\mathrm{U}-{ }^{14} \mathrm{C}\right]$ glutamine (sp. act. $283 \mathrm{mCi} / \mathrm{mmol}$ ), $\mathrm{NaH}^{14} \mathrm{CO}_{3}$, and ${ }^{3} \mathrm{H}_{2} \mathrm{O}$ were purchased from New England Nuclear (Boston, $\mathrm{MA}$, U.S.A.). D-[5- $\left.{ }^{3} \mathrm{H}\right]$ Glucose (sp. act. $15 \cdot 7 \mathrm{Ci} / \mathrm{mmol}$ ) was purchased from Amersham International (Amersham, U.K.).

For culture of the embryos, the Ham's F-10 medium was supplemented with $100 \mathrm{i}$.u. penicillin $/ \mathrm{ml}, 100 \mu \mathrm{g}$ streptomycin $/ \mathrm{ml}, 25 \mathrm{~mm}-\mathrm{Hepes}$, and $0.4 \%$ (w/v) BSA. The $\mathrm{pH}$ was adjusted to 7.0 , and culture conducted under $5 \%$ $\mathrm{CO}_{2}$ in air, saturated with water, at $37^{\circ} \mathrm{C}$.

The culture apparatus (Fig. 1) consisted of inner wells which were cut from multi-well plates (Lux 5250, Miles Laboratories, Naperville, IL, U.S.A.), and placed in $400 \mu 125 \mathrm{~mm}-\mathrm{NaHCO}_{3}$, within wells of larger multi-well plates (Falcon 3047, Becton-Dickinson, Lincoln, NJ, U.S.A.).

Embryo collection and pre-culture. Embryos were collected at Day 7 of gestation (Day $0=$ day of first detected oestrous behaviour) from groups of 3-5 superovulated Holstein heifers, as previously described (King et al., 1987). The embryos were isolated from the collection medium, pooled, washed 4 times in culture medium, and cultured in $1 \mathrm{ml}$ medium overnight.

Immediately before the experimental culture period, the blastocysts were pooled, washed in fresh medium, and randomly divided among wells containing either pure culture medium (untreated controls), or culture medium containing the appropriate metabolic treatment (DNP or PES) at twice the indicated concentration.

Experimental culture. The labelled substrates were dried under nitrogen and taken up in culture medium to give a nominal concentration of $0.25 \mu \mathrm{Ci} / \mu \mathrm{l}$, and final specific activities of $20 \cdot 4,14 \cdot 9,15 \cdot 0,7 \cdot 1$ and $86.8 \mathrm{mCI} / \mathrm{mmol}$ for D- $\left[5-{ }^{3} \mathrm{H}\right]$ glucose, $\mathrm{D}-\left[1-{ }^{14} \mathrm{C}\right]$ glucose, $\mathrm{D}-\left[6-{ }^{14} \mathrm{C}\right]$ glucose, $\left[2-{ }^{14} \mathrm{C}\right]$ pyruvate and $\mathrm{L}-\left[\mathrm{U}-{ }^{14} \mathrm{C}\right] \mathrm{glutamine}$, respectively. 
Individual embryos were taken up in $2 \mu$ culture medium (with or without metabolic effectors) and placed in the centre of the inner well of the culture apparatus. To this were added $2 \mu$ lof the labelled substrate solution, to produce a microdroplet with a total volume of $4 \mu \mathrm{l}$. The total number of disintegrations per minute (d.p.m.) of labelled substrate was determined by mixing $2 \mu \mathrm{l}$ samples of the labelled substrate solution with $400 \mu \mathrm{l} 25 \mathrm{~mm}$-sodium bicarbonate and counting as described below.

Three sham preparations were included for each combination of labelled substrate and metabolic treatment (control, DNP or PES). These contained $2 \mu \mathrm{l}$ of the labelled substrate solution and $2 \mu \mathrm{l}$ culture medium (with or without metabolic effectors) but no embryo, and served to control for all non-specific counts arising from machine background, chemiluminescence, bacterial contamination, and spontaneous breakdown of the labelled substrate.

The plates were equilibrated under $5 \% \mathrm{CO}_{2}$ in air for $15 \mathrm{~min}$, sealed with self-adhesive polyester film (Falcon 3073, Becton-Dickinson), and incubated for $3 \mathrm{~h}$ at $37^{\circ} \mathrm{C}$. For experiments using ${ }^{14} \mathrm{C}$-labelled substrates, $50 \mu \mathrm{l} 1.0 \mathrm{~N}-\mathrm{NaOH}$ were injected through the polyester film into the outer well via a 25-gauge needle at the end of the culture period to convert the dissolved $\mathrm{CO}_{2}$ and bicarbonate to carbonate. The film was then removed and the contents of the outer bath were aspirated, mixed with $10 \mathrm{ml}$ scintillation fluid (HP/b, Beckman Instruments, Fullerton, CA, U.S.A.), and counted for $5 \mathrm{~min}$ in a liquid scintillation counter. The counts per minute were automatically corrected to d.p.m. by comparison of the scintillation pulse height distribution of the sample with those of a set of quench standards (Horrocks, 1980).

The embryos were then removed from the inner wells, pooled by treatment group and incubated for $48 \mathrm{~h}$ in fresh culture medium before evaluation of their development.

Estimation of product recovery. The efficiency of recovery of radiolabelled products was estimated at intervals from 0 to $180 \mathrm{~min}$ by placing known amounts of $\mathrm{NaH}^{14} \mathrm{CO}_{3}$ or ${ }^{3} \mathrm{H}_{2} \mathrm{O}$ in $4-\mu 1$ microdroplets of culture medium, and culturing them exactly as for the embryos. At the end of each period, the outer bath of $400 \mu \mathrm{l} \mathrm{NaHCO}$ was aspirated and counted. The recovery efficiency was expressed as the percentage of radioactivity found in the outer bath fluid.

Calculation of substrate utilization. The amount of substrate consumed by each embryo was calculated in a fashion similar to that proposed by Hunter \& Sadler (1987). The mean d.p.m. for the appropriate sham wells were first subtracted from the d.p.m. for each embryo. The difference was divided by the total d.p.m. of labelled substrate added, and multiplied by the total quantity of substrate in the $4 \mu$ l droplet, and corrected for recovery efficiency (see 'Results' section).

Statistical analysis. Differences in metabolic activity between embryos cultured with and without metabolic effectors were evaluated using the Mann-Whitney U-test (Guilford \& Fruchter, 1973).

\section{Results}

Figure 2 shows that the maximum recovery of both ${ }^{14} \mathrm{CO}_{2}$ and ${ }^{3} \mathrm{H}_{2} \mathrm{O}$ was reached within 30 min. For all determinations between 30 and $180 \mathrm{~min}$ the recovery averaged $49 \pm 4.4 \%$ (mean \pm s.d., $n=21)$ and $60 \pm 5 \cdot 4 \%(n=18)$, for ${ }^{14} \mathrm{CO}_{2}$ and ${ }^{3} \mathrm{H}_{2} \mathrm{O}$, respectively. These values were assumed to represent the efficiency of recovery in the embryo experiments and therefore the results presented below include a correction factor of $2.04(100 / 49)$ for experiments using ${ }^{14} \mathrm{C}$-labelled substrates, and $1.67(100 / 60)$ for the experiment using $\left[5-{ }^{3} \mathrm{H}\right]$ glucose. Machine counting efficiency ranged from 89 to $90 \%$ for ${ }^{14} \mathrm{C}$ and from 55 to $57 \%$ for ${ }^{3} \mathrm{H}$.

Table 1 summarizes the results of all determinations of metabolic activity for individual embryos. Measurable substrate metabolism by individual embryos, defined as d.p.m. greater than the mean sham d.p.m. +2 s.d., was detected for all substrates except for $\left[6-{ }^{14} \mathrm{C}\right]$ glucose in the presence of PES (Exp. II). The absolute number of counts recovered from the sham wells never significantly exceeded that of the background counts of the scintillation counter when ${ }^{14} \mathrm{C}$-labelled glucose or glutamine were used as substrates. However, for $\left[5-{ }^{3} \mathrm{H}\right]$ glucose and $\left[2-{ }^{14} \mathrm{C}\right]$ pyruvate, the sham values were 50 and 30 times background, respectively.

The apparent metabolism of glucose varied markedly, depending on the position of the radiolabel, as indicated by the contrasts among the results for the control groups of Exps I, II and III. The mean production of ${ }^{3} \mathrm{H}_{2} \mathrm{O}$ from $\left[5-{ }^{3} \mathrm{H}\right]$ glucose was 16 -fold greater than the production of $\mathrm{CO}_{2}$ from carbon 1 of glucose, and it, in turn, was 14-fold greater than the production of $\mathrm{CO}_{2}$ from carbon 6 .

DNP did not have any significant stimulatory effect on the metabolism of glucose, regardless of the position of the radiolabel. Conversely, the metabolism of glutamine increased by $50 \%$ in the presence of DNP and that of pyruvate doubled.

The production of $\mathrm{CO}_{2}$ from carbon 1 of glucose increased almost 5-fold in the presence of PES, but PES had no effect on either the production of ${ }^{3} \mathrm{H}_{2} \mathrm{O}$ from $\left[5-{ }^{3} \mathrm{H}\right]$ glucose or on the production of 


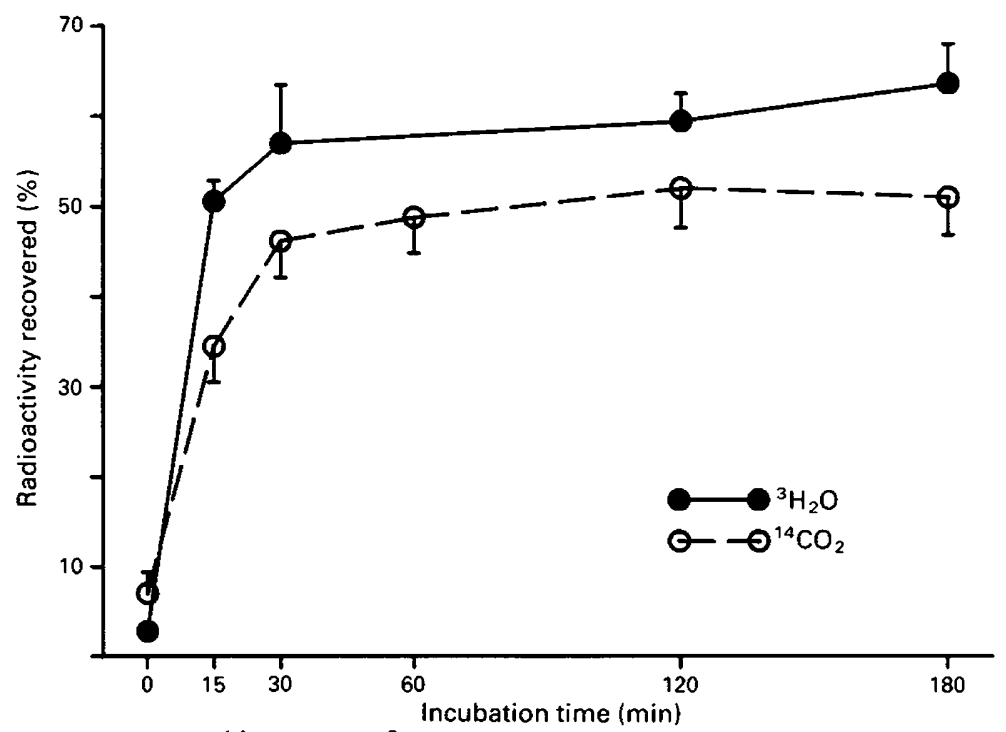

Fig. 2. The recovery of ${ }^{14} \mathrm{CO}_{2}$ and ${ }^{3} \mathrm{H}_{2} \mathrm{O}$ in the outer well of the culture apparatus from $\mathrm{NaH}^{14} \mathrm{CO}_{3}$ and ${ }^{3} \mathrm{H}_{2} \mathrm{O}$, respectively, placed in the inner well. Each point represents the mean $( \pm$ s.d.) of 6 determinations.

Table 1. The metabolism of glucose, pyruvate, and glutamine by individual cattle blastocysts

\begin{tabular}{|c|c|c|c|c|}
\hline Exp. & $\begin{array}{l}\text { Labelled } \\
\text { substrate }\end{array}$ & Treatment & $\begin{array}{l}\text { No. of } \\
\text { embryos }\end{array}$ & $\begin{array}{l}\text { Substrate consumed } \\
(\mathrm{pmol} / \mathrm{embryo} / 3 \mathrm{~h})\end{array}$ \\
\hline \multirow[t]{2}{*}{ I } & $\mathrm{D}-\left[1-{ }^{14} \mathrm{C}\right] \mathrm{Glucose}$ & $\begin{array}{c}\text { Control } \\
50 \mu \mathrm{M}-\mathrm{DNP}\end{array}$ & $\begin{array}{l}6 \\
6\end{array}$ & $\begin{array}{r}9.8 \pm 3.5 \\
11.6 \pm 3.9\end{array}$ \\
\hline & $\mathrm{D}-\left[6^{-{ }^{14}} \mathrm{C}\right]$ Glucose & $\begin{array}{c}\text { Control } \\
50 \mu \mathrm{M}-\mathrm{DNP}\end{array}$ & $\begin{array}{l}6 \\
6\end{array}$ & $\begin{array}{l}0.6 \pm 0.4 \\
0.8 \pm 0.2\end{array}$ \\
\hline \multirow[t]{2}{*}{ II } & $D-\left[1 .{ }^{14} \mathrm{C}\right]$ Glucose & $\begin{array}{c}\text { Control } \\
25 \mu \mathrm{M}-\mathrm{PES}\end{array}$ & $\begin{array}{l}6 \\
6\end{array}$ & $\begin{array}{c}9 \cdot 8 \pm 3 \cdot 6 \\
47 \cdot 4 \pm 28 \cdot 6^{a}\end{array}$ \\
\hline & $D-\left[6-{ }^{14} \mathrm{C}\right]$ Glucose & $\begin{array}{c}\text { Control } \\
25 \mu \mathrm{M}-\mathrm{PES}\end{array}$ & $\begin{array}{l}5 \\
6\end{array}$ & $\begin{array}{c}0.8 \pm 0.6 \\
\text { Undetectable }\end{array}$ \\
\hline III & $\mathrm{D}-\left[5-{ }^{3} \mathrm{H}\right] \mathrm{Glucose}$ & $\begin{array}{c}\text { Control } \\
50 \mu \mathrm{M}-\mathrm{DNP} \\
25 \mu \mathrm{M}-\mathrm{PES}\end{array}$ & $\begin{array}{l}5 \\
5 \\
5\end{array}$ & $\begin{array}{l}161 \cdot 3 \pm 65 \cdot 2 \\
183 \cdot 8 \pm 46 \cdot 7 \\
118 \cdot 0 \pm 61 \cdot 5\end{array}$ \\
\hline IV & $\mathrm{L}-\left[\mathrm{U}-{ }^{14} \mathrm{C}\right]$ Glutamine & $\begin{array}{c}\text { Control } \\
50 \mu \mathrm{M}-\mathrm{DNP}\end{array}$ & $\begin{array}{l}6 \\
6\end{array}$ & $\begin{array}{l}1.4 \pm 0.4 \\
2.1 \pm 0.5^{b}\end{array}$ \\
\hline V & $\mathrm{L}-\left[\mathrm{U}-{ }^{14} \mathrm{C}\right]$ Glutamine & $\begin{array}{l}\text { Control } \\
25 \mu \mathrm{M}-\mathrm{PES}\end{array}$ & $\begin{array}{l}4 \\
5\end{array}$ & $\begin{array}{l}1.7 \pm 0.3 \\
1.1 \pm 0.3^{b}\end{array}$ \\
\hline VI & {$\left[2-{ }^{14} \mathrm{C}\right]$ Pyruvate } & $\begin{array}{c}\text { Control } \\
50 \mu \mathrm{M}-\mathrm{DNP}\end{array}$ & $\begin{array}{l}7 \\
6\end{array}$ & $\begin{array}{l}47 \cdot 3 \pm 24 \cdot 2 \\
94 \cdot 7 \pm 49 \cdot 8^{b}\end{array}$ \\
\hline
\end{tabular}

All values are mean \pm s.d.

${ }^{\text {a }} P<0.01$ compared with the preceding control group.

${ }^{b} P<0.05$ compared with the preceding control group.

$\mathrm{CO}_{2}$ from carbon 6 . The metabolism of glutamine was significantly decreased by $33 \%$ in the presence of PES.

The measurement of metabolic activity in the absence of treatment, or in the presence of $50 \mu \mathrm{M}$ DNP had no noticeable effect on the morphological condition of the blastocysts. Their subsequent 
development through hatching and post-hatching expansion in vitro did not differ from that of embryos not subjected to the measurement technique. Conversely, all embryos cultured in the presence of $25 \mu \mathrm{M}$-PES were retracted at the end of the measurement period, and failed to develop.

\section{Discussion}

In this study, the metabolic activity of cattle blastocysts was measured during culture under an atmosphere of $5 \% \mathrm{CO}_{2}$, in Ham's F-10 medium, which contains vitamins, fatty acids, and a wide range of amino acids, in addition to glucose and pyruvate. Although the exact requirements for bovine embryo development are unknown, Ham's F-10 medium supported blastocyst development through hatching and post-hatching expansion, and is considered to be the medium of choice for culture of cattle embryos (see Wright \& Bondioli, 1981).

O'Fallon \& Wright (1986) measured the metabolic activity of individual mouse embryos in a microdroplet of culture medium suspended above a $0.1 \mathrm{~N}$ solution of $\mathrm{NaOH}$. The $\mathrm{NaOH}$ served both as a trap for ${ }^{14} \mathrm{CO}_{2}$ produced from the metabolism of ${ }^{14} \mathrm{C}$-labelled glucose, and as an exchange reservoir for the collection of ${ }^{3} \mathrm{H}_{2} \mathrm{O}$ produced from the metabolism of $\left[5-{ }^{3} \mathrm{H}\right] \mathrm{glucose}$. Our technique relies on the same principle for the recovery of ${ }^{3} \mathrm{H}_{2} \mathrm{O}$, but differs in the way ${ }^{14} \mathrm{CO}_{2}$ is exchanged with the $\mathrm{CO}_{2}$ in the air space and then with the bicarbonate in the outer bath, instead of being trapped in $\mathrm{NaOH}$.

When $\left[5-{ }^{3} \mathrm{H}\right]$ glucose or $\left[2-{ }^{14} \mathrm{C}\right]$ pyruvate was used as the labelled substrate, the counts produced by the non-specific transfer of radioactivity from the culture droplet to the external bath (as measured in the sham wells) differed significantly from machine background value, even though this represented less than $0.35 \%$ of the total radioactivity added. The reason for this non-specific transfer is unknown but may have arisen from a minor contamination of the labelled substrate with other labelled compounds. In the case of $\left[5-{ }^{3} \mathrm{H}\right]$ glucose, it is possible that the tritium label is somewhat labile.

Glutamine and pyruvate are metabolized by the mitochondrial enzymes of the Krebs' cycle. The fact that significant quantities of these substrates were converted to $\mathrm{CO}_{2}$ indicates that the Krebs' cycle is active in the Day- 7 cattle blastocyst. The activity of the Krebs' cycle was stimulated in the presence of $50 \mathrm{~mm}-\mathrm{DNP}$, as indicated by the marked increase in the metabolism of pyruvate and glutamine. This differs from the observation that Krebs' cycle activity is maximal in Day-7 rabbit blastocysts (Benos \& Balaban, 1980).

The production of ${ }^{3} \mathrm{H}_{2} \mathrm{O}$ from $\left[5-{ }^{3} \mathrm{H}\right]$ glucose is accomplished by dehydration of 2-phosphoglycerate to phosphoenolpyruvate (PEP), and thus serves as a measure of the total flux of glucose through the Embden-Meyerhof pathway and the pentose shunt (see O'Fallon \& Wright, 1986). Our results indicate that relatively large quantities of glucose are metabolized to PEP by cattle blastocysts. However, the inclusion of $50 \mathrm{mM}$-DNP had no significant effect on the production of ${ }^{3} \mathrm{H}_{2} \mathrm{O}$ from $\left[5-{ }^{3} \mathrm{H}\right] \mathrm{glucose}$, or on the production of ${ }^{14} \mathrm{CO}_{2}$ from $\left[1-{ }^{14} \mathrm{C}\right]$ glucose or $\left[6-{ }^{14} \mathrm{C}\right] \mathrm{glucose}$, even though the same concentration of DNP markedly increased the activity of the Krebs' cycle, as indicated by its effect on the metabolism of pyruvate and glutamine.

Together, these observations suggest that the Krebs' cycle plays a limited role in the metabolism of glucose by the bovine blastocyst. If glucose can be metabolized to PEP, and pyruvate can be metabolized in the Krebs' cycle, then the block to the aerobic metabolism of glucose must be due to a lack or inhibition of pyruvate kinase, the enzyme responsible for the conversion of PEP to pyruvate.

The production of ${ }^{14} \mathrm{CO}_{2}$ from $\left[1-{ }^{14} \mathrm{C}\right]$ glucose and $\left[6-{ }^{14} \mathrm{C}\right]$ glucose, relative to the production of ${ }^{3} \mathrm{H}_{2} \mathrm{O}$ from $\left[5-{ }^{3} \mathrm{H}\right]$ glucose, can be used to evaluate the relative activities of the pentose shunt and the Embden-Meyerhof pathways (Katz \& Wood, 1963). O'Fallon \& Wright (1986) have used this approach to determine the relative pentose shunt activity of mouse embryos, and reported that it represented $3 \cdot 2 \%$ of the total metabolism of glucose by late blastocysts. Using the same calculations, 
our results would suggest that the pentose shunt accounts for $2 \cdot 0 \%$ of the glucose metabolized by the bovine blastocyst.

The observation that $25 \mu \mathrm{M}$-PES significantly increases the metabolism of carbon 1 of glucose by the bovine blastocyst indicates that, as for the mouse embryo (O'Fallon \& Wright, 1986), the pentose shunt operates at only a fraction of its potential. However, the deterioration of the blastocysts in the presence of PES probably limited the total expression of the potential of the pentose shunt. Similarly, the reduction in overall glucose and glutamine metabolism may have been due to cellular death rather than to a direct effect of PES.

O'Fallon \& Wright (1986) also reported that the production of ${ }^{14} \mathrm{CO}_{2}$ from $\left[6-{ }^{14} \mathrm{C}\right] \mathrm{glucose}$ was delayed by $\sim 2 \mathrm{~h}$ relative to the production of ${ }^{14} \mathrm{CO}_{2}$ from $\left[1-{ }^{14} \mathrm{C}\right]$ glucose and ${ }^{3} \mathrm{H}_{2} \mathrm{O}$ from [5$\left.{ }^{3} \mathrm{H}\right]$ glucose, which they attributed to a delay in the equilibration of $\left[6-{ }^{14} \mathrm{C}\right]$ glucose with the intracellular metabolic pools. However, in a similar study of the glucose metabolism of horse spermatozoa, we found that the time course of production of ${ }^{14} \mathrm{CO}_{2}$ from $\left[6-{ }^{14} \mathrm{C}\right]$ glucose was not different from that from $\left[1-{ }^{14} \mathrm{C}\right]$ glucose (D. Rieger, E. Palmer \& D. Vaillancourt, unpublished observations). Consequently, we cannot attribute the relatively low production of ${ }^{14} \mathrm{CO}_{2}$ from $\left[6-{ }^{14} \mathrm{C}\right] \mathrm{glucose}$ by bovine blastocysts to any such delay in equilibration of the substrate, and believe that it resulted from the partial or complete inactivity of pyruvate kinase.

It has been well established that glycolytic activity is low or blocked in early rabbit (Fridhandler, 1961; Brinster, 1969; Quinn \& Wales, 1973) and mouse (Brinster, 1965, 1969) embryos, and then increases markedly by the morula stage. The investigations of Barbehenn et al. $(1974,1978)$ indicated that this results from an inhibition of phosphofructokinase, probably by high levels of citrate which arise from a block of its metabolism in the Krebs' cycle. However, to our knowledge, the present report is the first indication that glycolysis in mammalian embryos may be blocked by a lack or inhibition of pyruvate kinase, and that a block to glycolysis can exist in the blastocyst.

Like phosphofructokinase, pyruvate kinase is an important regulatory enzyme in glycolysis, is inhibited by ATP and citrate, is irreversible, and does not, therefore, participate in gluconeogenesis. The block to glycolysis in mouse and rabbit embryos may serve to conserve glucose for some subsequent period of glucose deficiency or increased energy demand (see Rieger, 1984), and the inhibition of pyruvate kinase in the bovine blastocyst may serve the same purpose. The fact that this block exists at a much later developmental stage may be related to the relatively long pre-attachment period of the bovine embryo, compared to the pre-implantation period of mouse and rabbit embryos.

Our observation that glutamine can be metabolized to $\mathrm{CO}_{2}$ by the mammalian embryo, and thus serve as an energy substrate, in no way indicates whether or not this is of any physiological significance. However, in view of the importance of glutamine to the development of the hamster embryo (Carney \& Bavister, 1987), the role of glutamine as an energy substrate for bovine (and other mammalian) embryos deserves further study.

In conclusion, we have shown that, in cattle blastocysts, glucose is metabolized by the pentose shunt and the Ebden-Meyerhof pathway, as far as phosphoenol pyruvate. Although both pyruvate and glutamine are metabolized via the Krebs' cycle, glucose is not, indicating that glycolysis is blocked in the bovine blastocyst due to a lack or inhibition of pyruvate kinase.

We thank our colleagues at the CRRA, and Dr K. J. Betteridge, for their advice and support. Financial support for this work was provided by the Natural Sciences and Engineering Research Council of Canada, and le Ministère de l'enseignement supérieur, de la science et de la technologie du Québec.

\section{References}

Barbehenn, E.K., Wales, R.G. \& Lowry, H.L. (1974) The explanation for the blockade of glycolysis in early mouse embryos. Proc. natn. Acad. sci. U.S.A. 71, 1056-1060.
Barbehenn, E.K., Wales, R.G. \& Lowry, H.L. (1978) Measurement of metabolites in single preimplantation embryos; a new means to study metabolic control in early embryos. J. Embryol. exp. Morph. 43, 29-46. 
Benos, D.J. \& Balaban, R.S. (1980) Energy requirements of the developing mammalian blastocyst for active ion transport. Biol. Reprod. 23, 941-947.

Biggers, J.D. \& Stern, S. (1973) Metabolism of the pre-implantation mammalian embryo. Adv. Reprod. Physiol. 6, 1-59.

Brinster, R.L. (1965) Studies on the development of mouse embryos in vitro. II. The effect of energy source. J. exp. Zool. 158, 59-68.

Brinster, R.L. (1969) Radioactive carbon dioxide production from pyruvate and lactate by the preimplantation rabbit embryo. Expl Cell Res. 54, 205-209.

Carney, E.W. \& Bavister, B.D. (1987) Stimulatory and inhibitory effects of amino acids on the development of eight-cell embryos in vitro. J. In Vitro Fert. Emb. Trans. 4, 162-167.

Fridhandler, L. (1961) Pathways of glucose metabolism in fertilized rabbit ova at various pre-implantation stages. Expl Cell Res. 22, 303-316.

Guilford, J.P. \& Fruchter, B. (1973) Fundamental Statistics in Psychology and Education, pp. 220-225. McGraw-Hill, New York.

Horrocks, D. (1980) Effects of impurity and color quenching upon the liquid scintillation pulse height distributions. In Liquid Scintillation Counting: Recent Applications and Development, pp. 173-185. Eds C. Peng, D. Horrocks \& E. Alpen. Academic Press, New York.

Hunter, E.S. \& Sadler, T.W. (1987) Metabolism of Dand DL- $\beta$-hydroxybutyrate by mouse embryos in vitro. Metabolism 36, 558-561.

Katz, J. \& Wood, H.G. (1963) The use of $\mathrm{C}^{14} \mathrm{O}_{2}$ yields from glucose-1- and $-6-\mathrm{C}^{14}$ for the evaluation of the pathways of glucose metabolism. J. biol. Chem. 238, $517-523$.
King, W.A., Guay, P. \& Picard, L. (1987) A cytogenetical study of 7-day-old bovine embryos of poor morphological quality. Genome 29, 160-164.

O'Fallon, J.V. \& Wright, R.W. (1986) Quantitative determination of the pentose phosphate pathway in preimplantation mouse embryos. Biol. Reprod. 34, $58-64$.

Pike, I.L. (1981) Comparative studies of embryo metabolism in early pregnancy. J. Reprod. Fert., Suppl. 29, 203-213.

Quinn, P. \& Wales, R.G. (1973) The in vitro metabolism of [U- $\left.{ }^{14} \mathrm{C}\right]$ glucose by the preimplantation rabbit embryo. Aust. J. biol. Sci. 26, 653-667.

Renard, J.P., Menezo, Y., Saumande, J. \& Heyman, Y. (1978) Attempts to predict the viability of cattle embryos produced by superovulation. In Control of Reproduction in the Cow, pp. 398-417. Ed. J. R. Sreeman. Martinus Nijhoff, The Hague.

Renard, J.P., Menezo, Y. \& Heyman, Y. (1982) Alternative tests to assess viability of bovine embryos. Theriogenology 17, 106, Abstr.

Rieger, D. (1984) The measurement of metabolic activity as an approach to evaluating viability and diagnosing sex in early embryos. Theriogenology 21, 138-149.

Rieger, D., Lagneau-Petit, D. \& Palmer, E. (1987) Preliminary investigations of the metabolic activity of early horse embryos. J. Reprod. Fert., Suppl. 35, 699-700.

Wales, R.G. (1975) Maturation of the mammalian embryo: biochemical aspects. Biol. Reprod. 12, 66-81.

Wright, R.W. \& Bondioli, K.R. (1981) Aspects of in vitro fertilization and embryo culture in domestic animals. J. Anim. Sci. 53, 702-729.

Received 19 August 1987 